\title{
Health Monitoring and Diagnosis System for a Small H-Type Darrieus Vertical-Axis Wind Turbine
}

\author{
Sungmok Hwang *DiD and Cheol Yoo $\mathbb{D}$ \\ Wind Energy Research Team, Korea Institute of Energy Research (KIER), 200 Haemajihaean-ro, Gujwa-eup, \\ Jeji-si 63357, Jeju-do, Korea; c.yoo@kier.re.kr \\ * Correspondence: sm.hwang@kier.re.kr; Tel.: +82-64-800-2337
}

check for

updates

Citation: Hwang, S.; Yoo, C. Health Monitoring and Diagnosis System for a Small H-Type Darrieus Vertical-Axis Wind Turbine. Energies 2021, 14, 7246. https://doi.org/10.3390/en14217246

Academic Editor: Davide Astolfi

Received: 1 October 2021

Accepted: 26 October 2021

Published: 3 November 2021

Publisher's Note: MDPI stays neutral with regard to jurisdictional claims in published maps and institutional affiliations.

Copyright: (c) 2021 by the authors. Licensee MDPI, Basel, Switzerland. This article is an open access article distributed under the terms and conditions of the Creative Commons Attribution (CC BY) license (https:// creativecommons.org/licenses/by/ $4.0 /)$.

\begin{abstract}
As the wind power market grows rapidly, the importance of technology for real-time monitoring and diagnosis of wind turbines is increasing. However, most of the developed technologies and research mainly focus on large horizontal-axis wind turbines, and research conducted on small- and medium-sized wind turbines is rare. In this study, a novel low-cost and real-time health monitoring and diagnosis system for the small $\mathrm{H}$-type Darrieus vertical axis wind turbine is proposed. Turbine operating conditions were classified into parked/idle and power production. In the case of the power production condition, abnormality diagnosis was performed using key monitoring parameters, including vibration, fundamental frequency, the bending stress of the tower and generator vibration. The turbine abnormalities were diagnosed in two stages by applying the alert and alarm limits, determined by referring to international standards and material properties and the long-term measurement data together.
\end{abstract}

Keywords: small wind turbine; H-type Darrieus; vertical-axis wind turbine; health monitoring; diagnosis

\section{Introduction}

Interest in renewable energy and carbon-free energy sources has recently increased, resulting in wind energy coming into the spotlight as one of the most technically and economically efficient and practical alternatives. The wind power market is expected to grow rapidly in future, and, by 2050, the cumulative installed capacity of wind power plants worldwide is expected to reach about $3000 \mathrm{GW}$ onshore and about $480 \mathrm{GW}$ off-shore [1].

Operations and maintenance (O\&M) costs account for a large portion of the operating expenditure of wind turbines. Moreover, technological developments to reduce O\&M costs are being actively carried out by turbine manufacturers, maintenance experts and research institutes. The importance of health monitoring technology that can detect and predict failures by monitoring the operational status of wind turbines in real time is growing [2] Health monitoring of wind turbines can be categorized into condition monitoring (for mechanical and electrical machinery, including drive trains, generators and bearings) and structural health monitoring (for structural components such as blades, towers and foundations). There are international standards and guidelines established outlining the health monitoring of wind turbines [3-6]. The DNVGL service specifications specify the minimum requirements for measurement locations and sensors, measurement methods and analysis algorithms for condition monitoring of wind turbines [3]. Although the structural components, such as towers and blades, are also described, they are optional and are, to some extent, lower in importance than rotating machinery. The VDI 3834 standard also focuses on the requirements for rotating machinery and includes the requirements for tower vibration [4]. The VDI 4551 standard mainly focuses on the structural health monitoring of wind turbines and provides requirements for measurement locations, sensor type, the number and specification of sensors for measuring acceleration, inclination and 
deformation of structural components (including towers, transition pieces, substructures and foundation structures).

International standards and guidelines for health monitoring of the aforementioned wind turbines deal with large horizontal-axis wind turbines (HAWTs). Extensive research and review papers on health monitoring have also focused mainly on large HAWTs [2,7-22] because a HAWT is generally preferred for large-scale power generation due to its high efficiency and potential for power production. However, research conducted on the health monitoring of small- and medium-sized wind turbines is still rare. Small- and mediumsized wind turbines are mainly installed close to residential areas, such as rooftops and front yards of residential buildings. Thus, faults and failures in wind turbines can cause serious personal injury or property damage, and it is thus vital to monitor and diagnose the status of wind turbines continuously.

The health monitoring system employed for large-scale wind turbines can also be applied to small- and medium-sized wind turbines. However, it is not cost-effective to set up a health monitoring system, originally designed for monitoring large wind turbines, for monitoring small- and medium-sized wind turbines, as the cost of the health monitoring system is very high compared to that of the small- and medium-sized wind turbines. Additionally, small- and medium-sized wind turbines come in different forms [23]; thus, there are limitations when it comes to applying a health monitoring system, intended for large HAWTs, directly to small- and medium-sized wind turbines. Consequently, it is essential to optimize the health monitoring system to account for the cost and performance of each type and capacity of small- and medium-sized wind turbines.

This study introduces an optimized health monitoring system and diagnosis method for a small H-type Darrieus vertical-axis wind turbine (VAWT). Details of the small H-type Darrieus VAWT are presented in Section 2. Section 3 illustrates the actual implementation of the hardware for the health monitoring of the small H-type Darrieus VAWT. The measurement data and results of the analysis conducted during the long-term monitoring period are outlined in Section 4. Section 5 proposes the diagnostic criteria for the turbine by referring international standards, material properties and long-term measurement data together. The proposed novel system based on the diagnostic criteria is described in Section 6.

\section{Configuration of the Small H-Type Darrieus Vertical-Axis Wind Turbine}

This study examined a small H-type Darrieus VAWT installed in Jeju island in South Korea (as shown in Figure 1). Although it is a street lamp-type product, with a solar panel and battery installed together, only the small wind turbine (excluding the solar panel and lamp) was considered in this study. The configuration of the turbine is summarized in Table 1.

Table 1. Small H-type Darrieus VAWT configuration [24].

\begin{tabular}{ccc}
\hline Component & Parameter & Value \\
\hline & Diameter & $1 \mathrm{~m}$ \\
Length & $1.5 \mathrm{~m}$ \\
Weight & $15 \mathrm{~kg}$ \\
No. of Blades & 3 \\
Material & Cut-in Wind Speed & Expanded Polypropylene \\
& Rated Wind Speed & $2 \mathrm{~m} / \mathrm{s}$ \\
& Cut-out Wind Speed & $9 \mathrm{~m} / \mathrm{s}$ \\
& Type & $12 \mathrm{~m} / \mathrm{s}$ \\
\hline Renerator & Pated Power & $300 \mathrm{~W}$ \\
& Rotor Speed Range & $0 \sim 400 \mathrm{RPM}$ \\
& Pole Number & 10 \\
& Weight & $18 \mathrm{~kg}$ \\
\hline
\end{tabular}


Table 1. Cont.

\begin{tabular}{ccc}
\hline Component & Parameter & Value \\
\hline & Height & $6000 \mathrm{~mm}$ \\
Weight & $130 \mathrm{~kg}$ \\
Tower & Material & SS110 \\
& Bottom Diameter & $355 \mathrm{~mm}$ \\
& Bottom Thickness & $7 \mathrm{~mm}$ \\
& Top Diameter & $216 \mathrm{~mm}$ \\
& Top Thickness & $6 \mathrm{~mm}$ \\
\hline
\end{tabular}

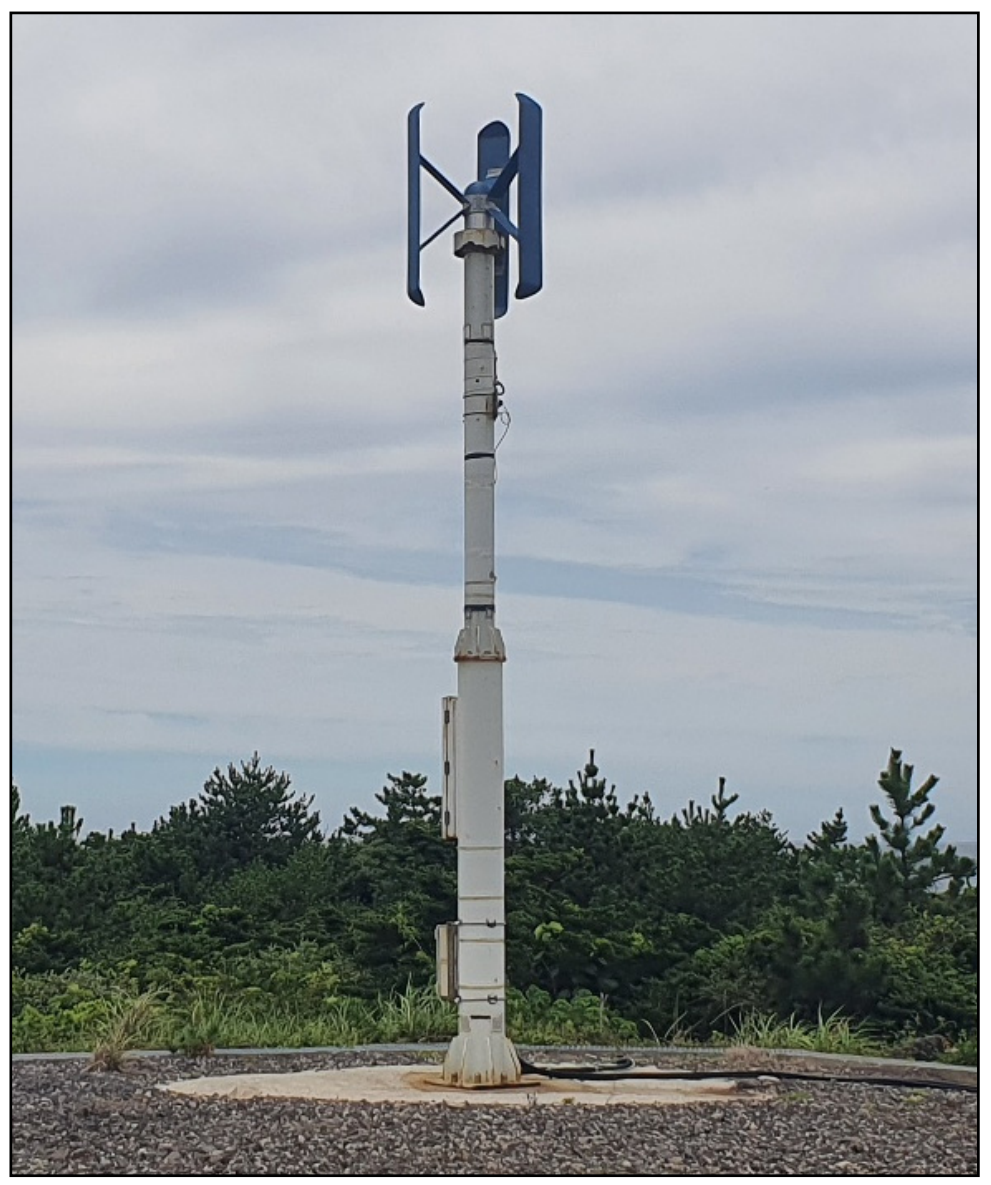

Figure 1. Small H-type Darrieus VAWT at the experimental site in Jeju Island, South Korea.

\section{Implementation of the Measurement System}

\subsection{Measurement Parameters}

3.1.1. Rotor Speed and Power

The power was calculated by measuring the voltage and current signals of the generator. Each rotation of the rotor generates a sinusoidal voltage wave with the number of cycles corresponding to half of the number of poles, and the number of cycles can be determined by counting the zero crossing of the sinusoidal waveform. Thus, the rotor speed in RPM was obtained from the zero crossing of the measured voltage signal in the time domain as follows:

$$
\text { Rotor Speed }=\frac{z c}{\text { Pole Number }} \times \frac{60}{T},
$$

where $z c$ is the total number of zero crossing of the voltage signal in the time domain during the measurement time, $T$, in sec. 


\subsubsection{Vibration Levels of the Generator and Tower}

The vibration level of the generator in the axial direction was measured by a single-axis accelerometer installed at the bottom of the generator housing. The tower vibrations in the east-west and south - north directions were measured by two single-axis accelerometers installed inside the top of the tubular tower. It would have been helpful to measure the vibration at the middle or lower position of the tower together for structural health monitoring; however, the vibration at the top of the tower was generally the largest. Thus, in this study, only the vibration at the top of the tower was factored in for calculating the hardware cost.

The natural frequencies of the tower were obtained by finding the Fourier transform peaks of the measured temporal variation signals of the tower. However, if the excitation frequencies are located near the natural frequencies of the tower, it is difficult to distinguish between the natural frequencies and excitation frequencies from the rotor and the blades. In this case, the natural frequencies can be more accurately detected when the wind turbine is in the idle condition.

\subsubsection{Mechanical Load of the Tower}

The strain of the tower in the east—west and south—north directions were measured by foil strain gauges with full-bridge configuration. The corresponding bending stress was then obtained through the formula:

$$
\sigma=E \varepsilon,
$$

where $\sigma$ is the calculated bending stress of the tower from the measured strain, $\varepsilon$, and the Young's Modulus of the tower material, $E=190 \mathrm{GPa}$. The bending moment, $M$, was calculated as follows:

$$
\begin{gathered}
M=E I \frac{\varepsilon}{r_{o}}, \\
I=\frac{\pi}{64}\left(r_{o}^{4}-r_{i}^{4}\right),
\end{gathered}
$$

where $r_{o}$ and $r_{i}$ are the outer and inner radius of the tower bottom, respectively. I indicates the moment of inertia.

In cases of bending stress and moment, the bottom of the tower generally shows the largest values; thus only the bending stress and moment at the tower bottom considered to calculate the hardware cost.

\subsection{DAQ Hardware Setup}

Figure 2 shows a configuration diagram of the implemented DAQ system for the health monitoring of the small H-type Darrieus VAWT. The voltage signal of the generator was directly connected to the NI 9219 module, and the current signal was converted to voltage by the current meter and connected to the NI 9219 module together. The three accelerometers (model-Dytran 3148e) installed at the generator and the tower were connected to the NI 9234 module. The strain gauges (model-Kyowa KFGS-5-350C1-11L1M3R) installed outside the bottom of the tubular tower were connected to the NI 9237 module. All these modules were then connected to the NI cDAQ-9189, which communicated to an industrial PC (model-Advantech UNO-2484-BTO). 


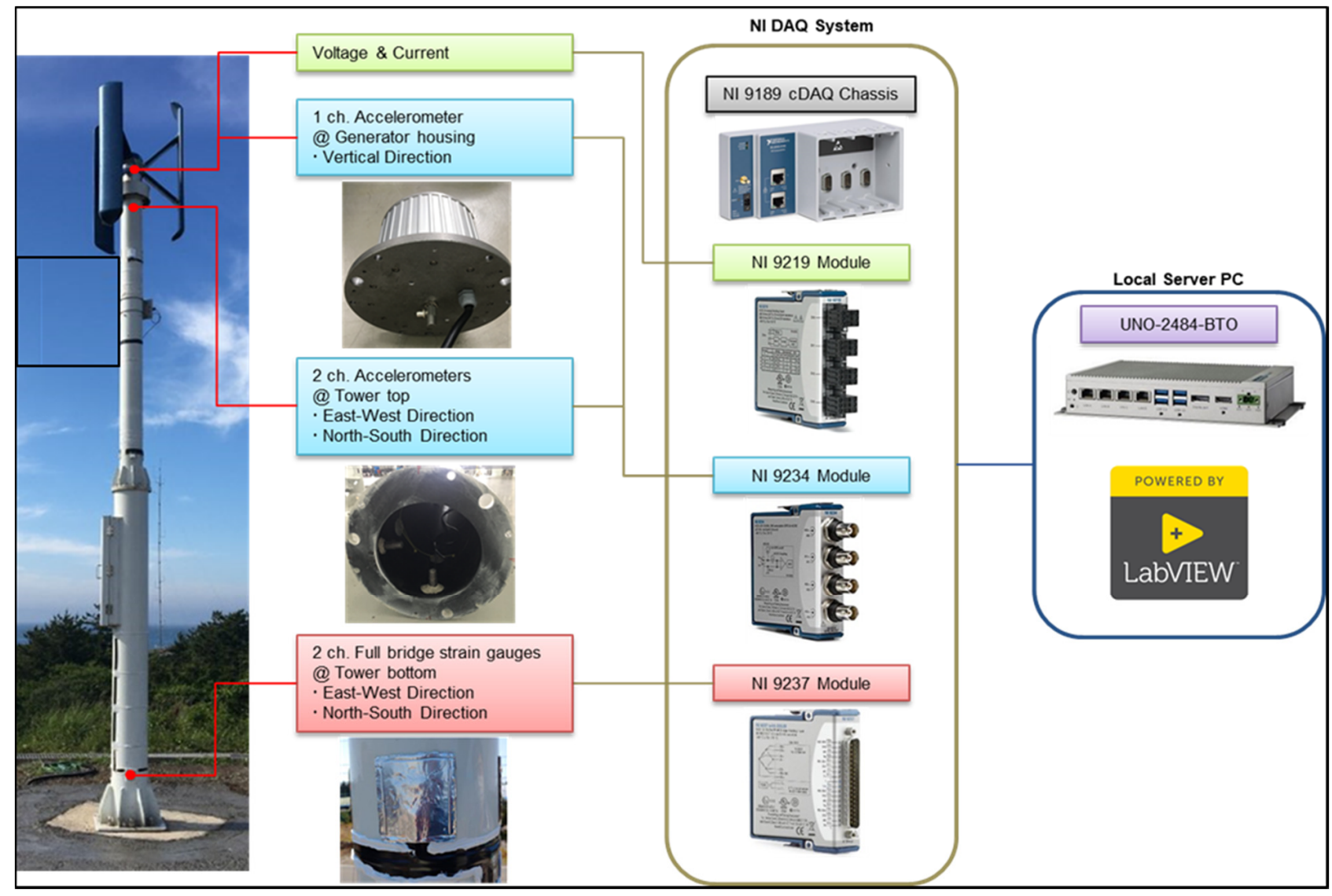

Figure 2. Configuration diagram of the health monitoring system for the small H-type Darrieus VAWT.

\subsection{Control Program}

All the signals were acquired at the sampling rate of $2048 \mathrm{~Hz}$ and stored every 1-min on the industrial PC installed inside the tower. The measurement system and data acquisition and storage were managed using the control program developed through LabVIEW, whose control panel is shown in Figure 3. 


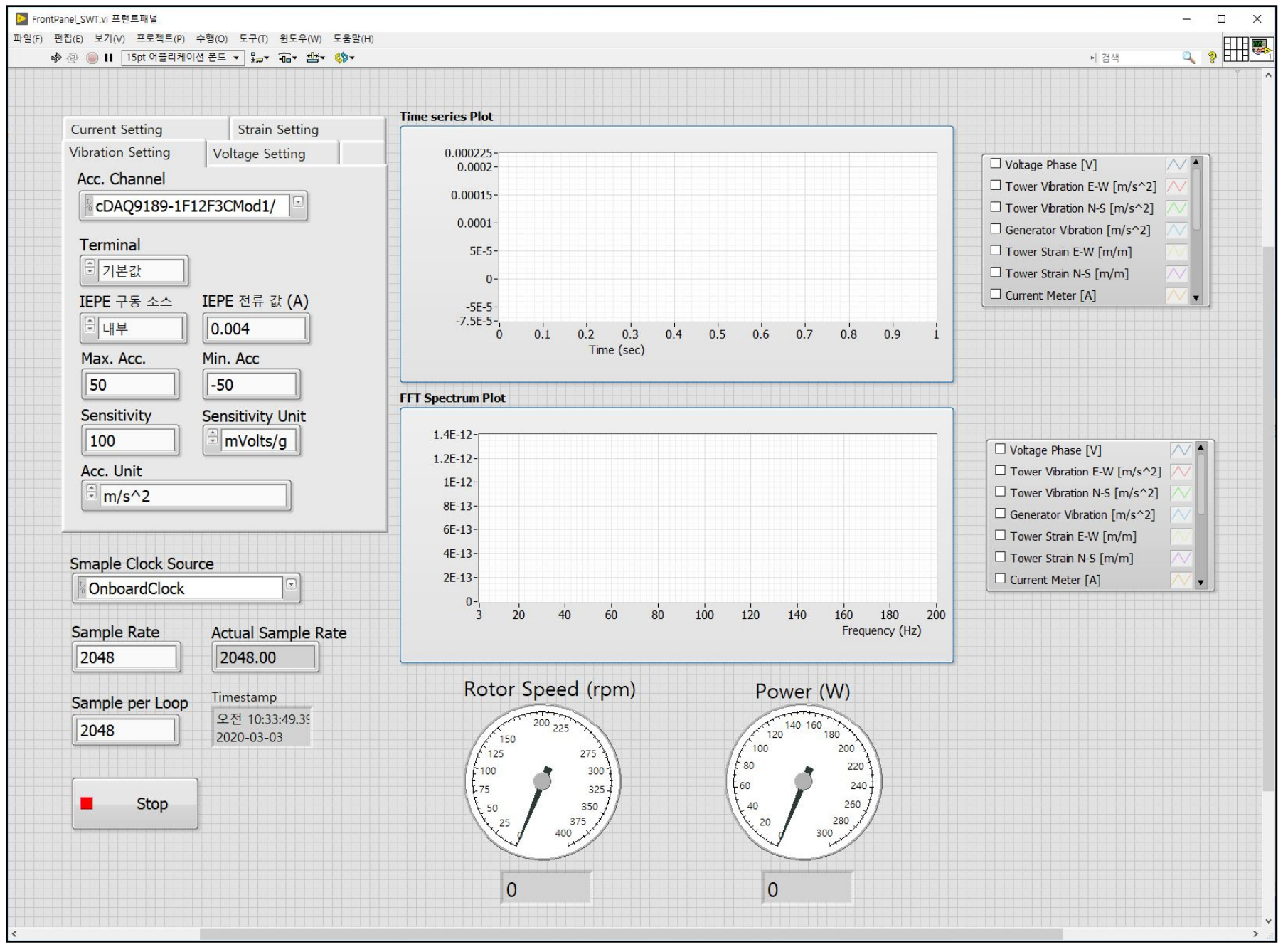

Figure 3. Screenshot of the control program developed by using LabVIEW.

\section{Long-term Monitoring and Analysis}

Long-term monitoring in this study refers to the simultaneous recording of voltage, current, vibration and strain signals, including the detailed analysis performed on the measured signals by considering the operating condition. Long-term monitoring is essential to analyze the dynamic characteristics of the turbine for each operating condition and evaluate its performance. Thus, in general, long-term monitoring is carried out before the commercialization of any new turbine.

In this study, the long-term monitoring of the small H-type Darrieus VAWT was performed from March 2021 to June 2021. During this monitoring period, a total of 61,364 1-min period data sets were obtained, excluding the idle and parked conditions. Figure 4 shows the number of 1-min period data sets at each rotor speed binned at 5 RPM. 


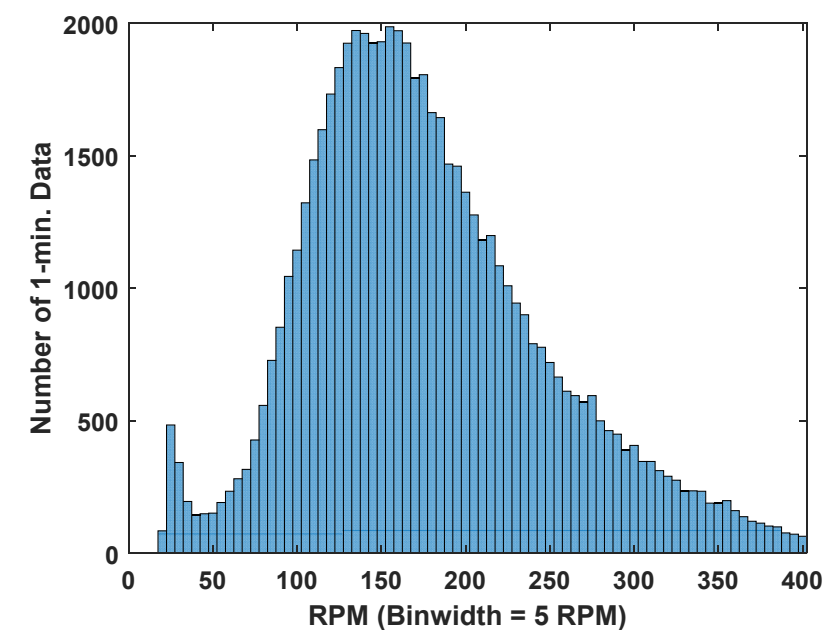

Figure 4. The number of 1-min period data sets at each rotor speed binned at 5 RPM (excluding the idle and parked conditions).

\subsection{Natural Frequencies of the Tower}

Determining the natural frequency of the entire tower structure is a good indicator to check for structural changes in the tower structure, such as cracks and bolt looseness. A hammering test was performed to determine the natural frequency of the tower in the idle condition. Figure 5 shows the measured signal in the time domain, whose frequency spectrum was obtained from the Fourier transform. By finding the peaks in the frequency spectrum, it was found that the first natural frequency of the tower was around $6 \mathrm{~Hz}$. No significant differences were observed between the natural frequencies in the east-west and south—north directions due to the symmetry of the small H-type Darrieus VAWT.
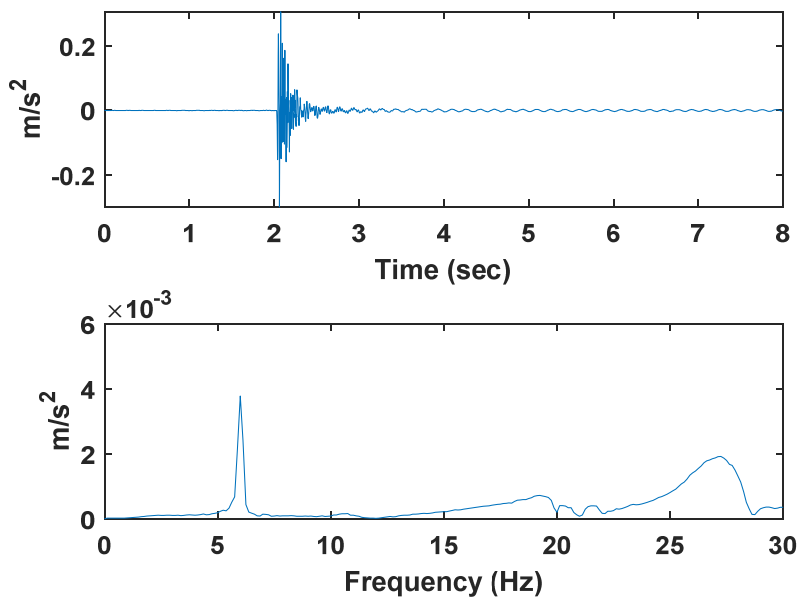

(a)
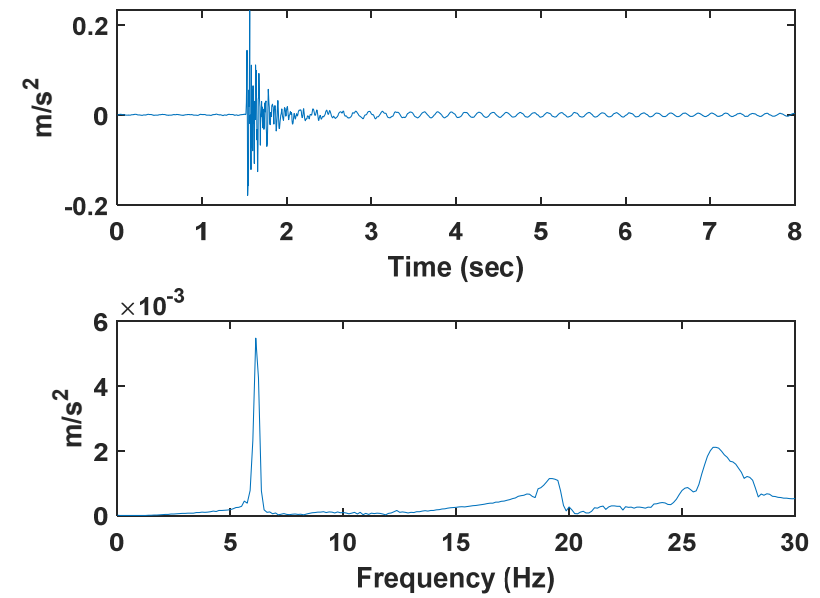

(b)

Figure 5. Hammering test results to measure the natural frequencies of the tower: (a) time series (top) and its frequency spectrum (bottom) in the east-west direction; (b) time series (top) and its frequency spectrum (bottom) in the south—north direction.

\subsection{Power Performance}

The power curve, representing the power output of a wind turbine as a function of the measured wind speed, is measured to evaluate the power performance during the performance test period of a newly developed wind turbine. Thus, one of the key elements of power performance testing is measuring wind speed. In this study, however, devices to measure wind speed and direction, such as an anemometer and wind vane, were not 
installed considering the cost of the health monitoring system of the small H-type Darrieus VAWT. In this case, the power produced, as a function of rotor speed, was a good alternative to analyze the power performance of the wind turbine.

Figure 6 shows the measured power output of the small H-type Darrieus VAWT, as a function of rotor speed in RPM. The second-order polynomial to fit the measured power output is also shown in Figure 6. The power output and rotor speed of the turbine indicate a clear relationship, and the power output can be fitted as the second-order polynomial of the rotor speed in RPM with high accuracy $\left(R^{2}=0.9990\right)$.

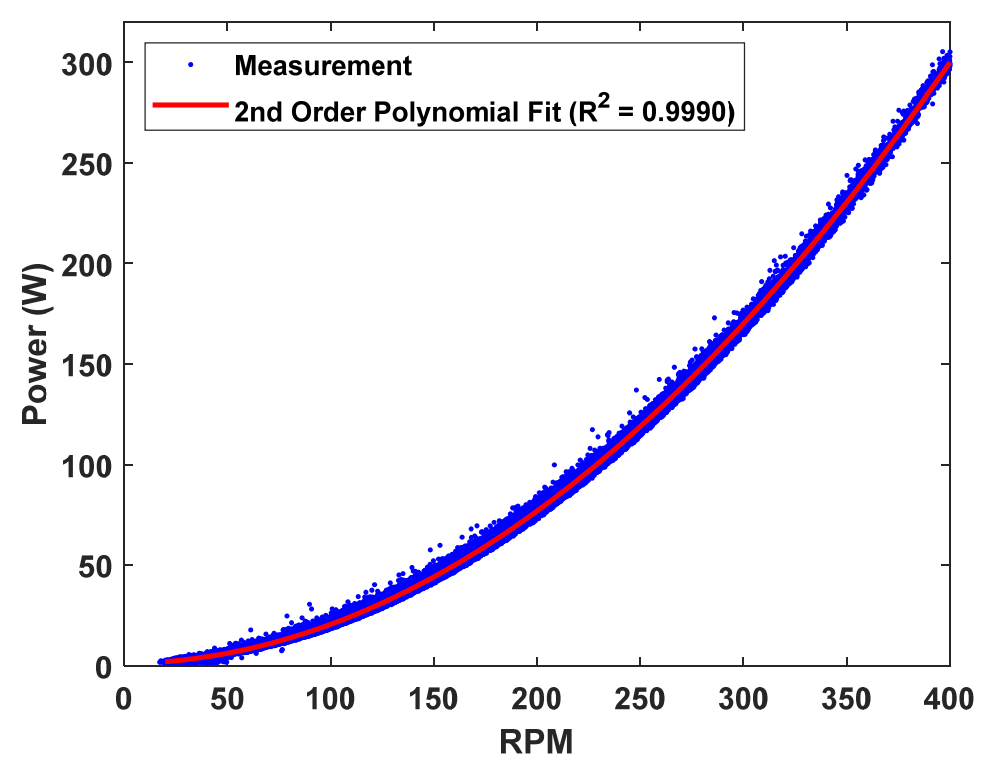

Figure 6. Rotor speed in RPM and the power output. The dotted points and solid line indicate the measured values and the second-order polynomial fitted line, respectively.

\subsection{Tower Vibration}

The root-mean-square (RMS) value is one of the most useful measures to represent the vibration level because it is directly related to the energy content of the vibration profile and the destructive capability of the vibration. In this study, from the vibration measured in the time domain, an acceleration RMS value, $a_{T}$, was defined to represent the vibration level of the tower, characterizing the total loading over an evaluation period $T_{0}$. This RMS value was obtained through the formula:

$$
a_{T}=\sqrt{\frac{1}{T_{0}} \int_{0}^{T_{0}} a_{f}^{2}(t) d t}
$$

where $a_{f}$ is the measured acceleration in the filtered time domain over the selected frequency range 1-1000 Hz. The desired frequency range was selected wide enough to represent all the dynamic characteristics of the tower structure.

Figure 7 shows the RMS values of the tower vibration for each 1-min data set in both the east—west $\left(a_{T, E W}\right)$ and the south—north $\left(a_{T, S N}\right)$ directions. Due to the symmetry of the small H-type Darrieus VAWT, the vibrations in the east-west and south-north directions showed almost the same RMS values and trends. In general, as the rotor speed increases, the excitation force also increases, and the vibration value tends to increase. It should be noted that the RMS values increased significantly to around 120 RPM and $360 \mathrm{RPM}$, and this was due to the structural resonance of the tower. As the turbine had a three-blade rotor, the vibration levels increased to about 120 RPM and 360 RPM, corresponding to the fundamental frequency of the tower at $6 \mathrm{~Hz}$, with the first and second blade passing frequency, respectively. However, even if resonance occurred close to 
120 RPM and 360 RPM, the maximum RMS values of the tower vibration at these RPMs were as good as $1 \mathrm{~m} / \mathrm{s}^{2}$ and $1.5 \mathrm{~m} / \mathrm{s}^{2}$, respectively.

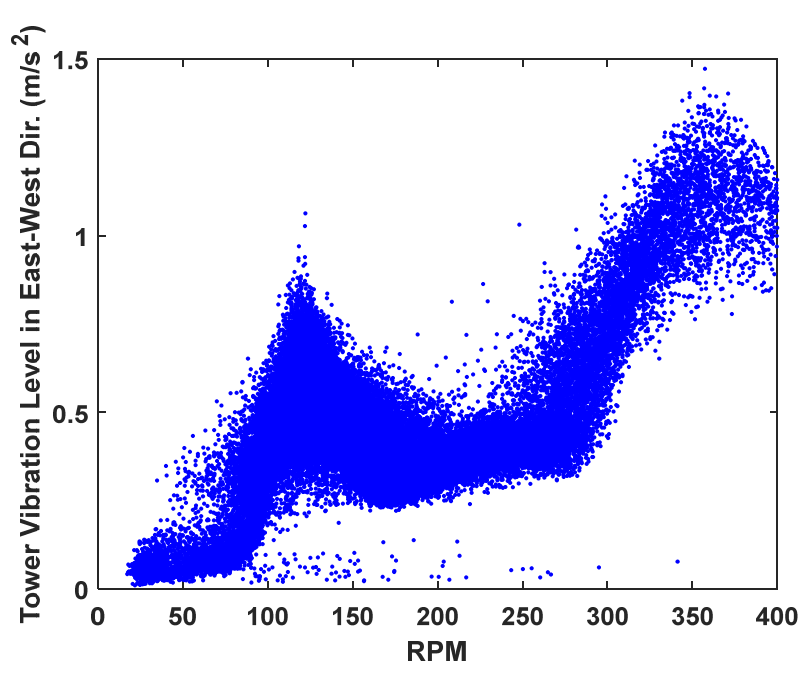

(a)

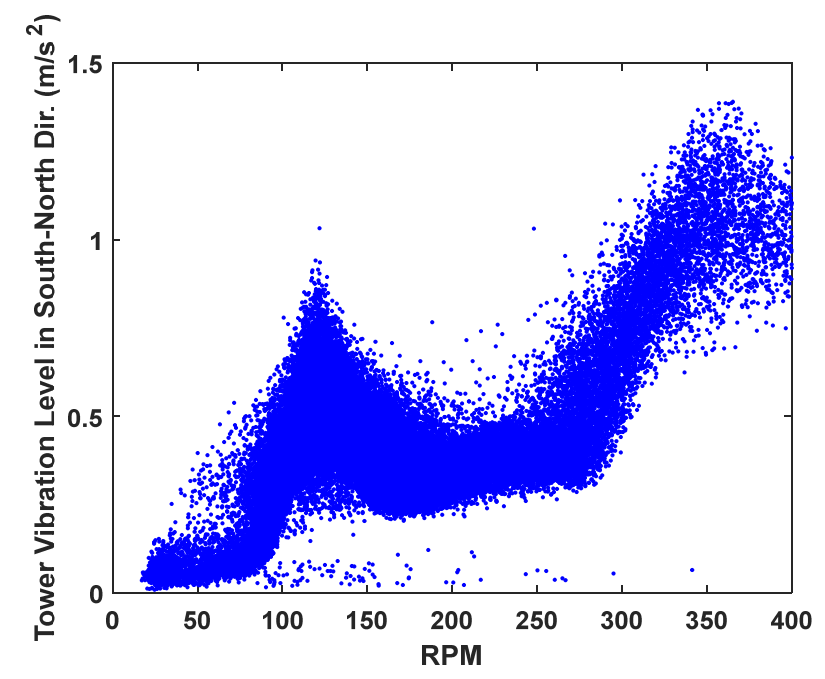

(b)

Figure 7. RMS values of the tower vibration for each 1-min data set: (a) vibration level in the east—west direction, $a_{T, E W}$; (b) vibration level in the south—north direction, $a_{T, S N}$.

\subsection{Generator Vibration}

In this study, following the vibration measurements in the time domain, a velocity RMS value, $v_{G}$, was defined to represent the vibration level of the generator in the axial direction. Similar to Equation (5), $v_{G}$ was obtained as follows:

$$
v_{G}=\sqrt{\frac{1}{T_{0}} \int_{0}^{T_{0}} v_{f}^{2}(t) d t},
$$

where $v_{f}$ is the measured velocity in the filtered time domain over the selected frequency range $10-1000 \mathrm{~Hz}$. The desired frequency range was selected wide enough to adequately cover the frequency spectrum of the generator.

Figure 8 shows the velocity RMS values of the generator vibration for each 1-min data set in the axial direction. The RMS value increased in the 150 RPM-250 RPM range, but it was still a good level, with a maximum of approximately $2 \mathrm{~mm} / \mathrm{s}$ or less. Although the generator was located at the top of the tower, there was no increase in the generator vibration, even at 120 RPM and 360 RPM, where the vibration of the tower increased significantly due to the structural resonance of the tower. This was due to the measurement direction of the generator vibration, i.e., the axial direction, which was perpendicular to the vibration directions of the tower-the east—-west and south—north directions. 


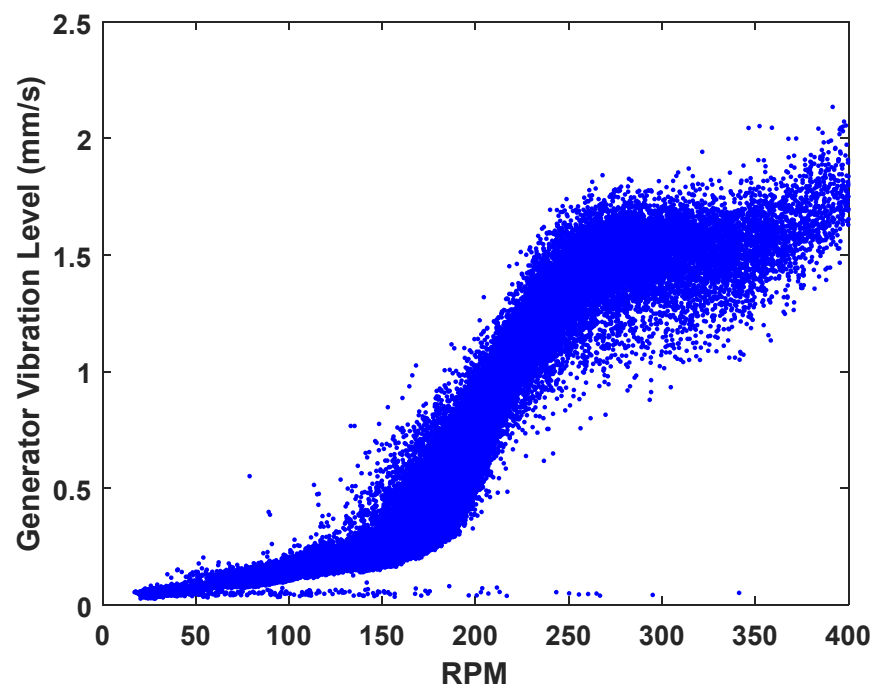

Figure 8. RMS values of the axial vibrations of the generator for each 1-min data set.

\subsection{Mechanical Load of the Tower}

From the measured strain of the tower, the bending stress and moment were calculated using Equations (2)-(4). Figure 9 shows the bending stress of the tower bottom and its corresponding bending moment in the east-west $\left(\sigma_{E W}\right)$ and south-north $\left(\sigma_{S N}\right)$ directions. Note that each dotted point represents the maximum value measured during the corresponding 1-min period. Similar to the tower vibration, due to the symmetry of the small H-type Darrieus VAWT, the bending stresses and moments in the east-west and south-north directions showed almost the same values and trends. The bending stress and moment of the tower increased slightly to around 120 RPM due to the structural resonance of the tower. However, the tower bending stress was low, with a maximum of approximately $20 \mathrm{MPa}$ or less.

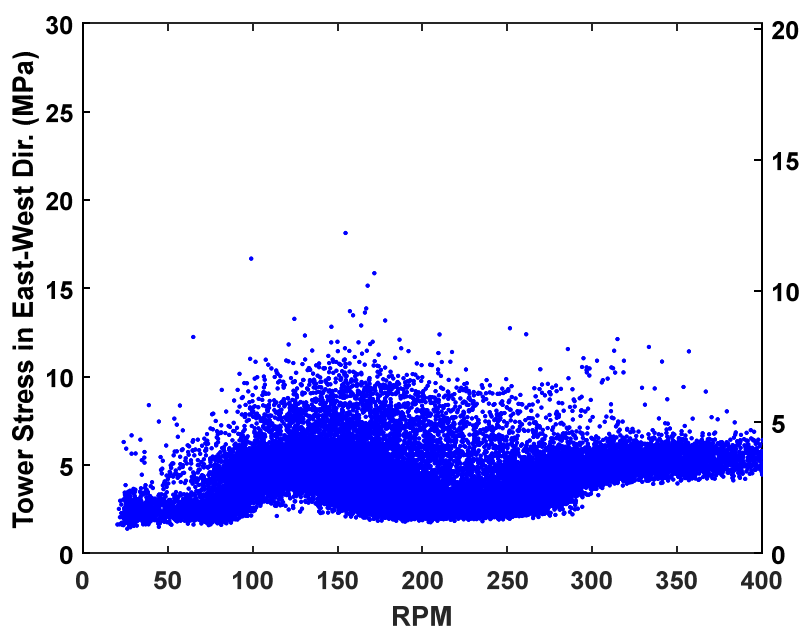

(a)

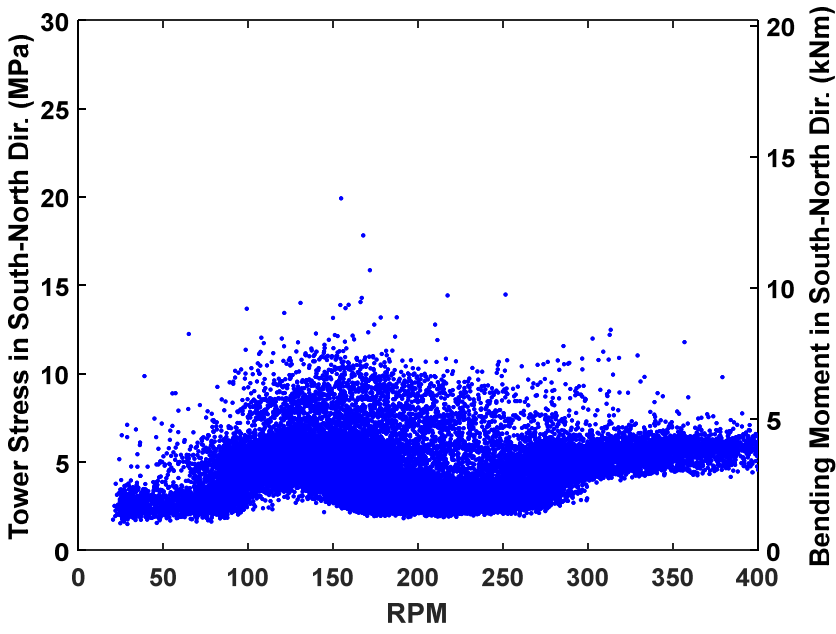

(b)

Figure 9. Measured tower bending stress (left axis) for each 1-min data set and the corresponding bending moment (right axis): (a) bending stress and moment in the east—west direction, $\sigma_{E W} ;(\mathbf{b})$ bending stress and moment in the south-north direction, $\sigma_{S N}$. 


\section{Diagnostic Criteria}

In this section, the algorithm for diagnosing the current operational status of the small H-type Darrieus VAWT, using real-time measurement signals such as power output, mechanical load and vibration, will be covered in detail.

\subsection{Operation Condition}

The operational status of wind turbines is divided into parked, idle and power production. The parked condition means to physically lock the rotor in a stationary position, with the rotor not being able to rotate with the wind or be moved by any other means. The idle condition means that the wind turbine is rotating slowly and not producing power. The power production condition indicates that a wind turbine is running and connected to an electric load.

In this study, the operational status of the wind turbine was determined by the power output value calculated using the measured generator voltage and current signals. The operational status of the wind turbine was classified as parked/idle (if the power output was less than $1 \mathrm{~W}$ ) and power production (for other power output values).

\subsection{Abnormality Diagnosis}

In the case of the power production condition, the turbine status was determined based on the measured vibration level, mechanical load level, natural frequency of the tower and the generator vibration level.

Many standards and guidelines related to condition monitoring lay down the limit values determined in multiple stages. In this study, two-stage limit values were determined for each of the measurement parameters. One limit value was defined as the trigger for a warning, i.e., an alert; and the second was an alarm.

\subsubsection{Alarm Limit}

An alarm appears when a specified limit value has been reached, indicating the limit value above which further operation of the wind turbine can cause critical damage to the wind turbine components. Once an alarm limit has been exceeded, the wind turbine should be shut down and remedial actions should be taken immediately.

Although several international standards, including the VDI 3834 [4] and ISO 20816-21 [25], recommend the limit applicable for the main components of a large HAWT with a gearbox, it is difficult to directly apply these standards to a small VAWT. Moreover, there are no standards stipulating an alarm limit applicable to the tower of a small VAWT. Thus, in this study, the alarm limit of the tower vibration for the small $\mathrm{H}$-type Darrieus VAWT, $a_{T, \text { alarm }}$, was conservatively determined as $2 \mathrm{~m} / \mathrm{s}^{2}$ based on the measurement database of the Korea Institute of Energy Research (the institute has been conducting performance tests for various small- and medium-sized wind turbines for over 15 years).

ISO 20816-1 provides general guidelines stipulating the vibration limit of rotating machines and can be used to set the alarm limit of the generator vibration measured on non-rotating parts. Considering the generator capacity of the small H-type Darrieus VAWT, the alarm limit of the generator vibration, $v_{G, \text { alarm }}$, was determined as $4.5 \mathrm{~mm} / \mathrm{s}$, corresponding to the zone boundary A/B value, specified in Table C.1 of ISO 20816-1 [25].

In the case of the bending stress of the tower, the yield strength of the tower material should first be considered because the material begins to deform plastically if the stress exceeds the yield strength. In this study, the alarm limit of the tower bending stress, $\sigma_{\text {alarm }}$, was determined as the yield stress, $\sigma_{\text {yield }}$, by considering the safety factor, $\gamma$. IEC 61400-2 recommends a safety factor of 3 for materials used for the ultimate strength analysis of small wind turbines [26].

In this study, the yield strength of the material is considered, but if a more conservative alarm limit is required, the fatigue limit of the material can be applied instead of the yield strength. 


\subsubsection{Alert Limit}

An alert offers advice that a significant change in the measured value has occurred and that the trend of the measured value should be observed attentively. When an alert appears, it is generally permissible to keep the wind turbine running until the cause of the significant change is identified, and, if necessary, remedial action is initiated.

Most of the standards and guidelines related to condition monitoring of wind turbines apply the limit value uniformly to all operating RPM ranges. However, rather than applying the alert limit value uniformly across all the operating RPM ranges, it is preferable to set different alert limit values for each operating RPM by considering the statistical values of the measurement results collected during the long-term monitoring period together. For example, even if the vibration value of the tower or generator is lower than the alarm limit when the rotor rotates at a low RPM, it is important to pay attention to the trend of the measured value if it is significantly higher than the previous measurement results.

Figure 10 shows the vibration RMS values of the generator for 1-min period data sets at each rotor speed binned at 5 RPM. The corresponding mean of the values (solid line) and the mean plus three standard deviations (dotted line) for each rotor speed binned at 5 RPM are also shown. Similar to Figures 10-12 show the maximum vibration RMS and maximum bending stress of the tower for each 1-min data set at each rotor speed binned at 5 RPM, respectively. Note that the maximum means the largest of the values in the east-west and south - north directions. In this study, the statistical values, i.e., the mean plus three standard deviations at each rotor speed was applied to the alert limits for the vibration and bending stress of the tower and the generator vibration.

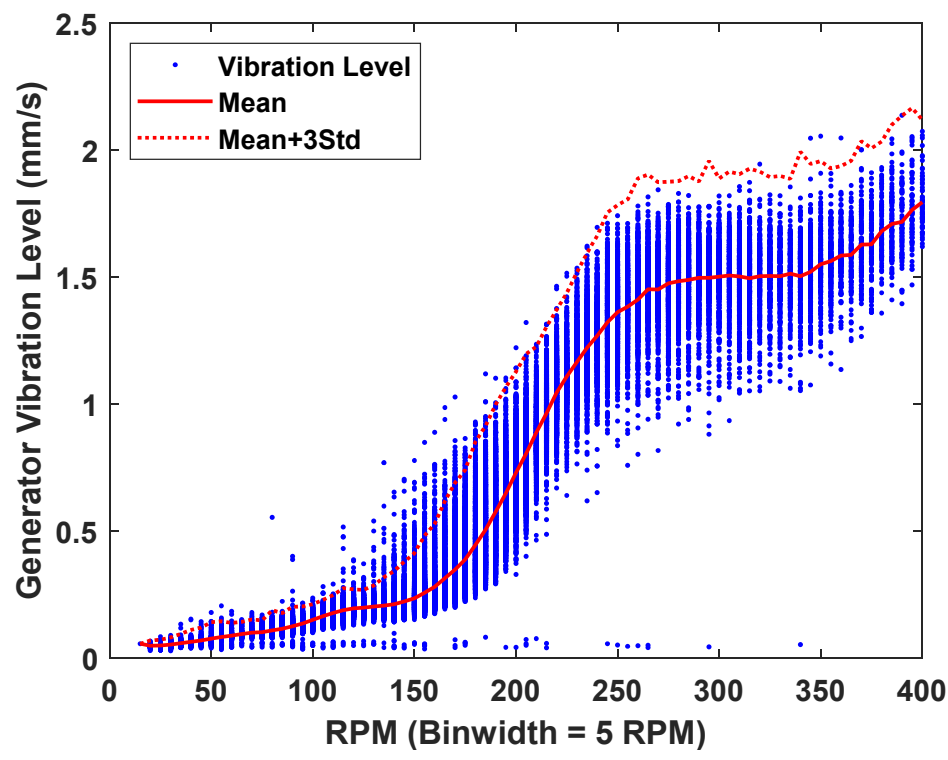

Figure 10. Vibration level of the generator for each 1-min data set. 


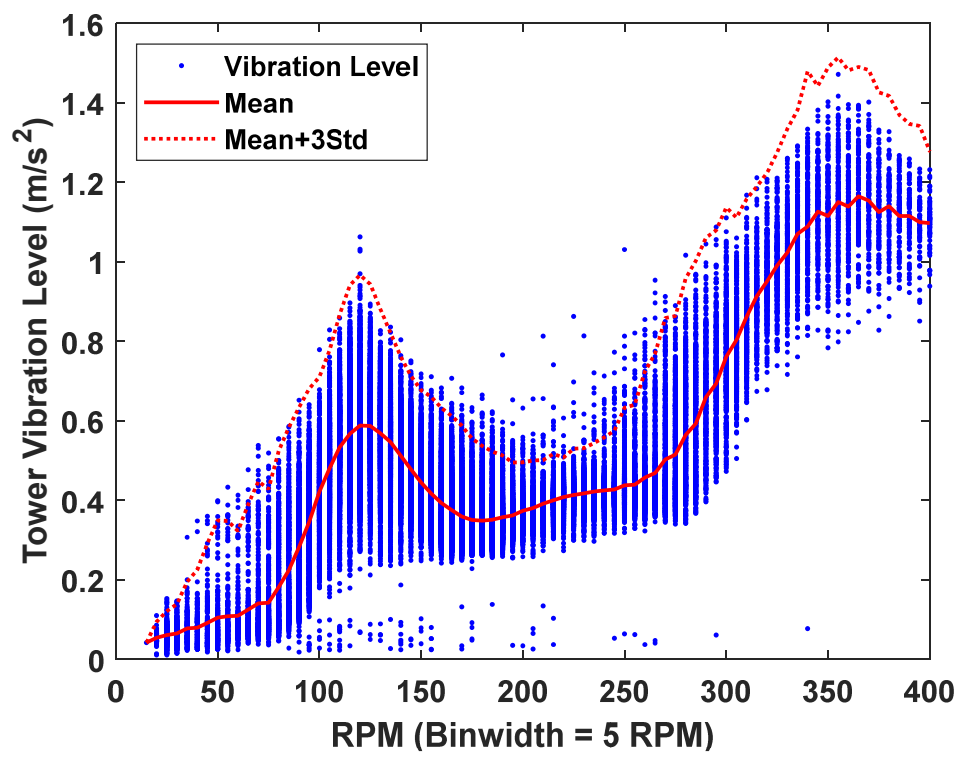

Figure 11. Maximum vibration level of the tower for each 1-min data set.

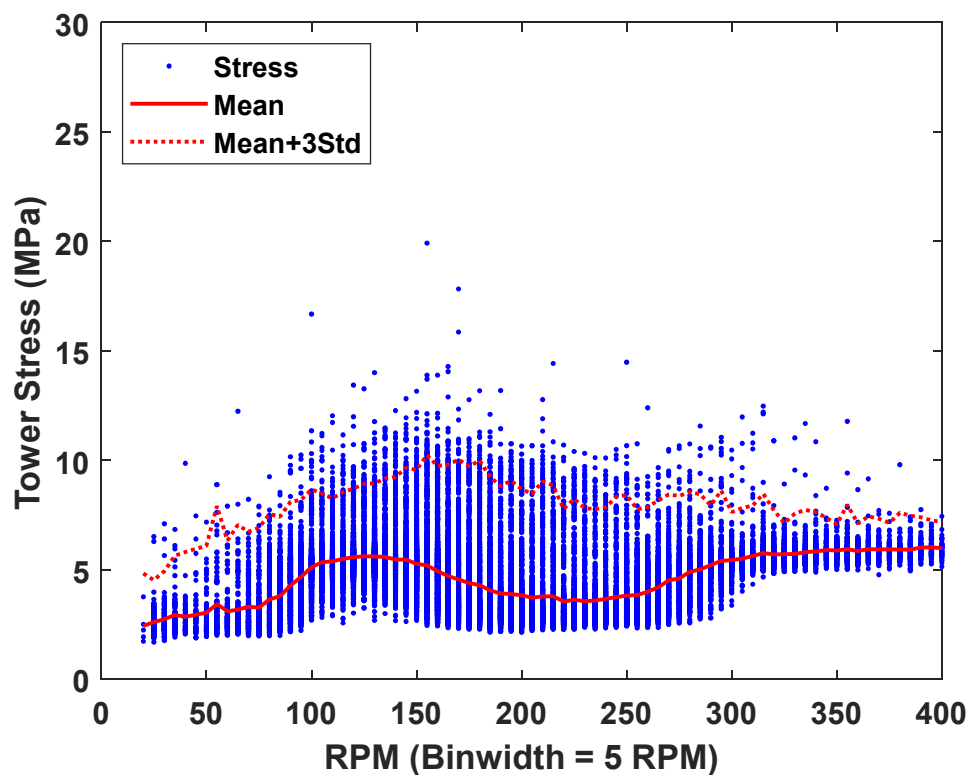

Figure 12. Maximum bending stress of the tower for each 1-min data set.

The natural frequency change is an important early indicator of structural changes. Several standards and guidelines recommend measuring and continuously monitoring the natural frequency change $[3-5,27,28]$. However, any limit value applicable to the natural frequency change is not described in the relevant references. In this study, the alert limit was set to a $10 \%$ change in the fundamental frequency of the tower based on experience. Therefore, an alert appeared when the measured fundamental frequency of the tower, $f_{0}$, was less than $10 \%$ of the reference value, $f_{\text {ref }}$. The reference value indicates the fundamental frequency of the tower measured during long-term monitoring, as described in Section 4.1.

The alert and alarm limits for each of the measurement parameters described above are summarized in Table 2 . In this study, $\sigma_{\text {yield }}=240 \mathrm{MPa}$ and $\gamma=3$. 
Table 2. Alert and alarm limits for each the measurement parameter.

\begin{tabular}{ccc}
\hline Parameter & Alert Limit & Alarm Limit \\
\hline Tower vibration $\left(a_{T, E W}\right.$ and $\left.a_{T, S N}\right)$ & $a_{T, \text { alert }}=$ Mean +3 Standard deviations & $a_{T, \text { alarm }}=2 \mathrm{~m} / \mathrm{s}^{2}$ \\
Generator vibration $\left(v_{G}\right)$ & $v_{G, \text { alert }}=$ Mean +3 Standard deviations & $v_{G, \text { alarm }}=4.5 \mathrm{~mm} / \mathrm{s}$ \\
Tower bending stress $\left(\sigma_{E W}\right.$ and $\left.\sigma_{S N}\right)$ & $\sigma_{\text {alert }}=$ Mean +3 Standard deviations & $\sigma_{\text {alarm }}=\sigma_{\text {yield }} / \gamma$ \\
Tower fundamental natural frequency $\left(f_{0}\right)$ & $f_{0}<0.9 f_{\text {ref }}$ & - \\
\hline
\end{tabular}

\section{Health Monitoring and Diagnosis System}

A health monitoring and diagnosis system for the small H-type Darrieus VAWT was developed using the measurement system described in Section 3 and the diagnostic criteria explained in Section 5. Figure 13 shows a flowchart of the main algorithm implemented for health monitoring and diagnosis. First, the power output was calculated from the raw data of the generator voltage and current signals measured during the 1-min intervals. If the power output was less than $1 \mathrm{~W}$, the turbine's operating condition was determined as parked/idle and terminated; if the output was greater than $1 \mathrm{~W}$, the turbine's operating condition was determined as power production, and the monitoring parameters, including the fundamental frequency of the tower, the vibration RMS values of the tower and the generator and the bending stress of the tower, were calculated from the measured raw data. Subsequently, it was determined whether the turbine was in a normal or abnormal condition. If the turbine status was abnormal, the diagnosis was further subdivided based on the alert and alarm limits. The above monitoring and diagnosis processes were performed repeatedly every minute.

The results of the health monitoring and diagnosis for the small $\mathrm{H}$-type Darrieus VAWT were displayed on the system screen in real time, as shown in Figure 14a. The measurement results, such as the rotor speed, power output, vibration level, natural frequency, bending moment of the tower and generator vibration level, were displayed together with the turbine status. The screen was updated every minute, and the measurement results and turbine status were stored in the format shown in Figure 14b. The turbine status index is an index indicating the diagnosis results. The cause of the alert or alarm, as shown in Table 3, was also indicated together if an alert or alarm appeared. Consequently, the current operating status and turbine health could be effectively monitored with only a small capacity and compact result data of $50 \mathrm{kB}$ per minute.

Table 3. Description of turbine status index.

\begin{tabular}{clcc}
\hline Status Index & Turbine Status & Diagnosis Result & Reason of Alert or Alarm \\
\hline 0 & Idle or Parked & - & - \\
\hline 1 & Power Production & Normal & - \\
\hline 2.1 & Power Production & Alert & Significant change of generator vibration \\
2.2 & Power Production & Alert & Chnificant change of tower vibration \\
2.3 & Power Production & Alert & Significant change of tower stress \\
2.4 & Power Production & Alert & Excessive generator vibration \\
3.1 & Power Production & Alarm & Excessive tower vibration \\
3.2 & Power Production & Alarm & Excessive tower stress \\
\hline 3.3 & Power Production & Alarm &
\end{tabular}




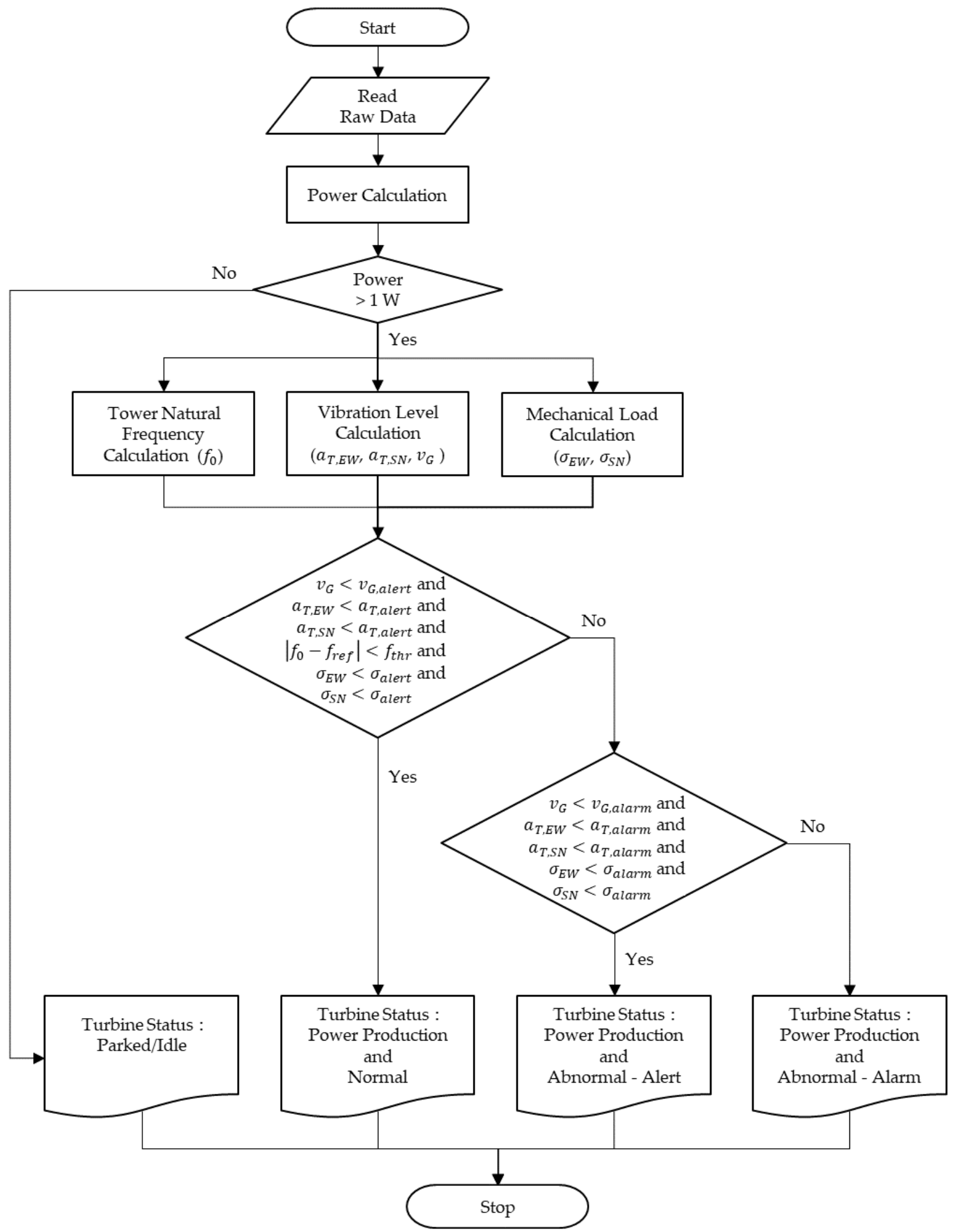

Figure 13. Flowchart of the main algorithm implemented for health monitoring and diagnosis. 


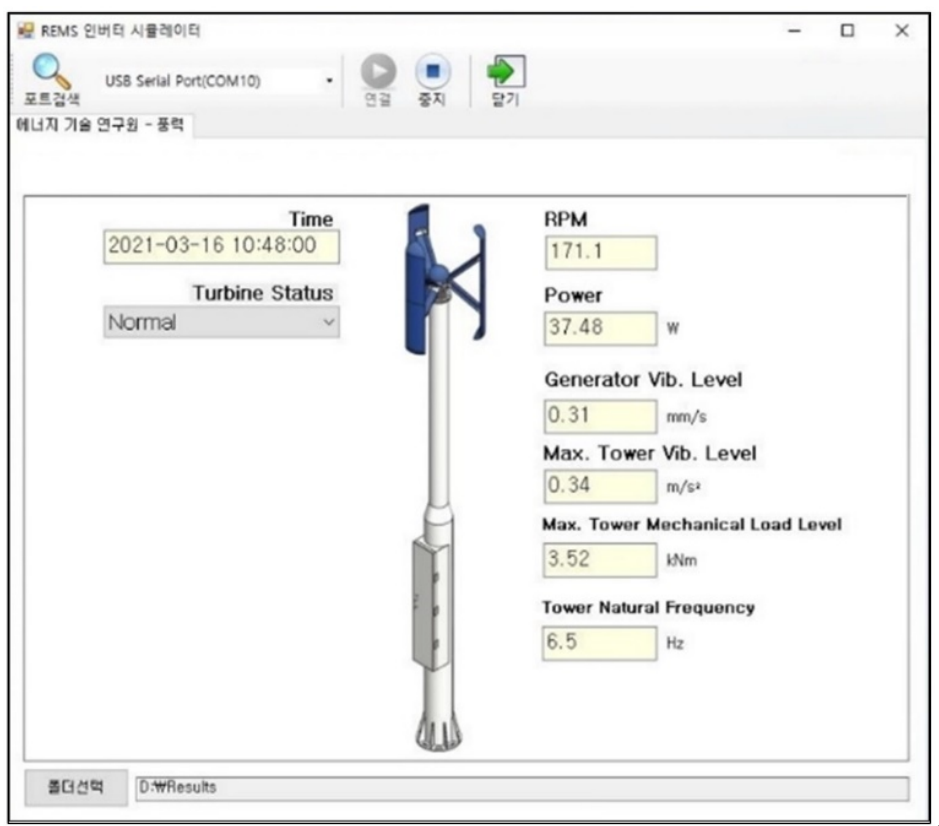

(a)

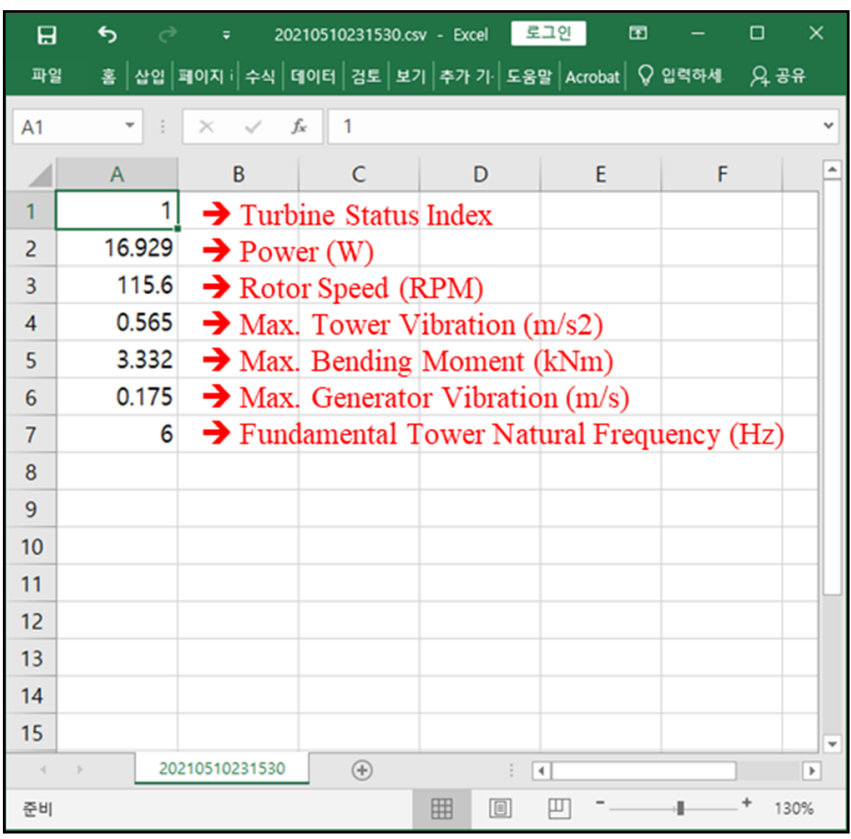

(b)

Figure 14. Health monitoring and diagnosis system for the small H-type Darrieus VAWT: (a) screenshot of the health monitoring and diagnosis system; (b) an example of the result file for each 1-min time interval along with its description.

\section{Discussion}

Small- and medium-sized wind turbines have recently begun coming into the spotlight as major power sources for distributed power systems alongside other power sources such as photovoltaics and fuel cells. However, for integrated monitoring and diagnosis of distributed power systems, it is essential to transmit various operational data of each power source to the integrated monitoring system. Data transmission through wireless communication is effective for long-distance transmissions; however, data capacity and transmission speed are directly related to cost, so it is important to reconsider this method and explore other alternatives. The health monitoring and diagnosis system developed in this study can be a potential solution because it was possible to efficiently monitor and diagnose the health of small wind turbines with only $50 \mathrm{kB}$ of data per minute.

It is vital to establish proper diagnostic criteria for the health monitoring and diagnosis of wind turbines. In this study, two-stage limits-the alert limit based on the long-term monitoring results and the alarm limit based on international standards and material properties-are proposed. It is common to conduct performance tests during the long time period before the commercialization of newly designed turbines. It is also preferable to set the alert limit using the measured data at this time. However, if long-term monitoring cannot be performed or if the data are unavailable, only the alarm limit can be applied at the time of initial installation. The alert limit, however, can be incorporated at a later stage, in addition to the alarm limit, when sufficient operational data is obtained.

As mentioned in Section 4.2, devices to measure wind speed and direction, such as a cup anemometer and wind vane, were not utilized in this study considering the cost of the health monitoring system. However, if installation is possible at a low cost, it is very helpful to obtain more relevant information on the power curve and to compare the levels of vibration and stress with wind speed. 


\section{Conclusions}

In this study, a low-cost real-time health monitoring and diagnosis system for the small H-type Darrieus VAWT is proposed. The turbine's operating condition was classified based on the power output: parked/idle and power production. In the case of the power production condition, the turbine status was determined based on the vibration, fundamental frequency, bending stress of the tower and the generator vibration. The turbine status was diagnosed in two stages by applying the alert and alarm limits.

In order to set the limit value, it is important not only to refer to international standards and material properties, but also to analyze the characteristics of the relevant wind turbine through long-term monitoring. In this study, the alarm limit was determined based on IEC and ISO standards and the yield strength of the tower material. If a more conservative limit value for the tower is required, the fatigue limit of the tower material can be utilized instead of the yield strength. The alert limit was determined for each operating RPM by considering the statistical values of the measurement results collected during the 4-month monitoring period.

The system proposed in this study can help in monitoring and diagnosing small wind turbines with only a small capacity and compact data. It can thus be effectively applied to distributed power systems requiring wireless transmission for remote monitoring.

Author Contributions: Conceptualization, S.H.; methodology, S.H. and C.Y.; software, S.H.; validation, S.H. and C.Y.; formal analysis, S.H.; investigation, C.Y.; resources, S.H. and C.Y.; data curation, S.H. and C.Y.; writing—original draft preparation, S.H.; writing—review and editing, S.H. and C.Y.; visualization, S.H.; supervision, S.H.; project administration, S.H.; funding acquisition, S.H. All authors have read and agreed to the published version of the manuscript.

Funding: This work was supported by (1) the New \& Renewable Energy Program of the Korea Institute of Energy Technology Evaluation and Planning (KETEP) granted financial resource from the Ministry of Trade, Industry \& Energy, Republic of Korea (No.20203010020050) and (2) the research and development program of the Korea Institute of Energy Research (C1-2421-02).

Institutional Review Board Statement: Not applicable.

Informed Consent Statement: Not applicable.

Data Availability Statement: Not applicable.

Acknowledgments: The authors would like to thank the journal editor and anonymous reviewers for their guidance and constructive suggestions.

Conflicts of Interest: The authors declare no conflict of interest.

\section{References}

1. Bloomberg, N.E.F. New Energy Outlook 2019 Dataset. 2019. Available online: https:/ /www.gihub.org/resources/publications/ bnef-new-energy-outlook-2019/ (accessed on 10 October 2021).

2. Wymore, M.L.; Van Dam, J.; Ceylan, H.; Qiao, D. A Survey of Health Monitoring Systems for Wind Turbines. Renew. Sustain. Energy Rev. 2015, 52, 976-990. [CrossRef]

3. DNVGL-SE-0439. Service Specification: Certification of Condition Monitoring. 2016. Available online: https://rules.dnv.com/ docs/pdf/DNV/SE/2016-06/DNVGL-SE-0439.pdf (accessed on 1 October 2021).

4. VDI 3834 Blatt 1:2015. Measurement and Evaluation of the Mechanical Vibration of Wind Turbines and Their Components-Wind Turbines with Gearbox. 2015. Available online: https://www.vdi.de/en/home/vdi-standards/details/vdi-3834-blatt-1measurement-and-evaluation-of-the-mechanical-vibration-of-wind-turbines-and-their-components-wind-turbines-withgearbox (accessed on 1 September 2021).

5. VDI 4551:2020. Structure Monitoring and Assessment of Wind Turbines and Offshore Stations. 2020. Available online: https: / /www.vdi.de/richtlinien/details/vdi-4551-structure-monitoring-and-assessment-of-wind-turbines-and-offshore-stations (accessed on 1 September 2021).

6. ISO 10816-21. Mechanical Vibration-Evaluation of Machine Vibration by Measurements on Non-Rotating Parts—Part 21: Horizontal Axis Wind Turbines with Gearbox; ISO: Geneva, Switzerland, 2015.

7. Antoniadou, I.; Dervilis, N.; Papatheou, E.; Maguire, A.E.; Worden, K. Aspects of structural health and condition monitoring of offshore wind turbines. Philos. Trans. R. Soc. A. 2015, 373, 20140075.

8. Escaler, X.; Mebarki, T. Full-Scale Wind Turbine Vibration Signature Analysis. Machines 2018, 6, 63. [CrossRef] 
9. Lian, J.; Cai, O.; Dong, X.; Jiang, Q.; Zhao, Y. Health Monitoring and Safety Evaluation of the Offshore Wind Turbine Structure: A Review and Discussion of Future Development. Sustainability 2019, 11, 494. [CrossRef]

10. Swartz, R.A.; Lynch, J.P.; Zerbst, S.; Sweetman, B.; Rolfes, R. Structural monitoring of wind turbines using wireless sensor networks. Smart Struct. Syst. 2010, 6, 183-196. [CrossRef]

11. Yang, W.; Tavner, P.J.; Crabtree, C.J.; Feng, Y.; Qiu, Y. Wind turbine condition monitoring: Technical and commercial challenges. Wind Energ. 2014, 17, 673-693. [CrossRef]

12. Zhang, S.; Jensen, T.L.; Franek, O.; Eggers, P.C.F.; Olesen, K.; Byskov, C.; Pedersen, G.F. UWB Wind Turbine Blade Deflection Sensing for Wind Energy Cost Reduction. Sensors 2015, 15, 19768-19782. [CrossRef] [PubMed]

13. Fischer, K.; Coronado, D.A. Condition Monitoring of Wind Turbines: State of the Art, User Experience and Recommendation; Fraunhofer Institute for Wind Energy and Energy System Technology IWES: Bremerhaven, Germany, January 2015; Available online: https:/ / www.vgb.org/vgbmultimedia/383_Final+report-p-9786.pdf (accessed on 15 September 2021).

14. Hameed, Z.; Hong, Y.; Cho, Y.; Ahn, S.; Song, C. Condition monitoring and fault detection of wind turbines and related algorithms: A review. Renew. Sustain. Energy Rev. 2009, 13, 1-39. [CrossRef]

15. Wenyi, L.; Zhenfeng, W.; Jiguang, H.; Guangfeng, W. Wind turbine fault diagnosis method based on diagonal spectrum and clustering binary tree SVM. Renew. Energy 2013, 50, 1-6. [CrossRef]

16. Besnard, F.; Bertling, L. An approach for condition-based maintenance optimization applied to wind turbine blades. IEEE Trans. Sustain. Energy 2010, 1, 77-83. [CrossRef]

17. García, F.P.; Tobias, A.M.; Pinar, J.M.; Papaelias, M. Condition monitoring of wind turbines: Techniques and methods. Renew. Energy 2012, 46, 169-178. [CrossRef]

18. Al-Ahmar, E.; Hachemi, M.E.; Turri, S. Wind energy conversion systems fault diagnosis using wavelet analysis. Int. Rev. Electr. Eng. 2008, 3, 646-652.

19. Yang, B.; Sun, D. Testing, inspecting and monitoring technologies for wind turbine blades: A survey. Renew. Sustain. Energy Rev. 2013, 22, 515-526. [CrossRef]

20. Yang, W.X.; Court, R.; Jiang, J.S. Wind turbine condition monitoring by the approach of SCADA data analysis. Renew. Energy 2013, 53, 365-376. [CrossRef]

21. Gill, S.; Stephen, B.; Galloway, S. Wind turbine condition assessment through power curve copula modeling. IEEE Trans. Sustain. Energy 2012, 3, 94-101. [CrossRef]

22. Duer, S.; Zajkowski, K.; Harni`cárová, M.; Charun, H.; Bernatowicz, D. Examination of multivalent diagnoses developed by a diagnostic program with an artificial neural network for devices in the electric hybrid power supply system "House on Water". Energies 2021, 14, 2153. [CrossRef]

23. Tummala, A.; Velamati, R.K.; Sinha, D.K.; Indraja, V.; Krishna, V.H. A Review on Small Scale Wind Turbines. Renew. Sustain. Energy Rev. 2016, 56, 1351-1371. [CrossRef]

24. Available online: http:/ / en.anytek.com/energy_category_detail/12?list_num=4\&category_num=5 (accessed on 14 July 2021).

25. ISO 20816-1. Mechanical Vibration-Measurement and Evaluation of Machine Vibration-Part 1: General Guidelines; ISO: Geneva, Switzerland, 2016.

26. IEC 61400-2. Wind Turbines-Part 2: Small Wind Turbines. 2013. Available online: https://standards.iteh.ai/catalog/standards/ iec/c442c95f-6b91-4995-b492-e9b82197c527/iec-61400-2-2013 (accessed on 15 September 2021).

27. DNVGL-ST-0438. Control and Protection Systems for Wind Turbines. 2016. Available online: https://rules.dnv.com/docs/pdf/ DNV/ST/2016-04/DNVGL-ST-0438.pdf (accessed on 1 September 2021).

28. NGI Report BSEE Offshore Wind Recommendations-Guidelines for Structural Health Monitoring for Offshore Wind Turbine Towers \& Foundations. 2017. Available online: https://www.bsee.gov/sites/bsee.gov/files/research-reports//770aa.pdf (accessed on 15 September 2021). 